\title{
Factors affecting head formation of iceberg lettuce (Lactuca sativa L.)
}

\author{
R. H. M. Maaswinkel and G. W. H. Welles
}

Glasshouse Crops Research Station, P.O. Box 8, 2670 AA Naaldwijk, Netherlands

Received 18 June 1986; accepted 2 December 1986

Key words: iceberg lettuce, Lactuca sativa, head formation, open heads, cultivars, temperature, fixed thermal screen.

\begin{abstract}
In a series of glasshouse experiments, performed in winter and spring from 1980 to 1985, head-forming properties of iceberg lettuce were studied. Differences between cultivars, effects of soil temperature and night air temperature, and application of a fixed thermal screen were studied in relation to the occurrence of open heads and head weight. Sinigicant differences in number of open heads between cultivars were observed. 'Starlina', 'Aubade', 'Cristallo' and 'Kellys' showed between 18 and $38 \%$ open heads, where 'Sonia' and 'Marbello' had less than $10 \%$ open heads. Head weight of 'Starlina' was lower than that of the other five cultivars, which did not significantly differ in yield.

In a pot experiment wih a peat mixture, 'Cristallo' showed a poor head formation when temperatures in the root enviroment lower than $14^{\circ} \mathrm{C}$ during the first part of the growing period were followed by higher temperatures thereafter. The number of open heads increased as the temparature shift was larger. Maintaining the root temperature above $14{ }^{\circ} \mathrm{C}$ throughout the growing period restulted in a low percentage of open heads. This experience was confirmed in a large-scale experiment in soil, where relative numbers of open heads decreased and head weights increased at higher soil and night air temperatures.

Application of a fixed thermal screen resulted in better head formation but lower head weights.

It is concluded that growing less sensitive cultivars and the use of a fixed thermal screen, in combination with relatively high soil and night air temperatures, seem to be most promising for improving head formation of iceberg lettuce.
\end{abstract}

\section{Introduction}

Iceberg lettuce is a crisphead type of lettuce with a solid spherical head. In the $\mathrm{Ne}$ therlands iceberg lettuce is grown under glass in winter, early spring, and autumn. 
In the winter period an economic production is endangered due to problems associated with head formation. Under these conditions the head initially closes but finally opens again. Also in the United Kingdom the acreage of iceberg lettuce is limited in this period of the year because of similar head quality problems (Norman, 1985).

In butterhead lettuce, head formation is closely related to leaf morphogenesis (Bensink, 1971). However, heads of butterhead lettuce develop from the outside to the inside, in contrast to the head formation in iceberg lettuce. It is known that for head formation of butterhead lettuce a high light intensity is favourable, whereas high temperatures delay the head formation process. Moreover, important differences in aptitude for head formation between different cultivars of butterhead lettuce have been noticed. Literature data about the influence of environmental factors on head formation of iceberg lettuce are scanty.

In the present paper, differences between cultivars, and effects of some environmental factors on head formation in iceberg lettuce will be described and evaluated. With that aim, several experiments were performed under glasshouse conditions in the winter periods from 1980 to 1985.

\section{Materials and methods}

In order to assess possible differences between cultivars with respect to head formation, six cultivars ('Starlina', 'Aubade', 'Cristallo', 'Kellys', 'Sonia' and 'Marbello') were grown in a heated glasshouse during winter and spring 1982. The experiment encompassed three different experimental sites and two replicates per site. Planting dates were all in early February. Percentages of open heads were determined regularly at harvests between early April and early May with 55 plants per replicate.

To study the effect of soil temperature on head formation, cv. 'Cristallo' was planted in plastic pots filled with a peat mixture on 19 December 1980. The pots were put in containers in which an adjusted temperature could be maintained. In this way the plants were grown at $6,10,14$ or $18^{\circ} \mathrm{C}$. When head formation started in the $14{ }^{\circ} \mathrm{C}$ treatment, 16 temperature combinations were arranged in four replicates by exchanging part of the pots from the four initial treatments. On 6 April, 16 plants per replicate were harvested and the percentages of open heads and head weights were determined.

In the experiments described above, setpoints for heating temperature were on an average $6{ }^{\circ} \mathrm{C}$ at night and $12{ }^{\circ} \mathrm{C}$ by day. Ventilation was switched on at $7{ }^{\circ} \mathrm{C}$ and $14^{\circ}$, respectively.

In order to study effects of soil temperature, night air temperature, and the use of a fixed thermal screen on the occurrence of open heads, two large-scale experiments were conducted. In one experiment two soil temperatures (unheated and $\left.14{ }^{\circ} \mathrm{C}\right)$ were each compared with two night air temperatures $\left(7\right.$ and $\left.10^{\circ} \mathrm{C}\right)$. For each treatment combination, the effect of the use of a fixed thermal screen was introduced as an additional objective. Under these conditions cv. 'Cristallo' was planted on 10 January and harvested on 30 March 1983. In an analogous experiment, the ef- 
fects of two night air temperatures $\left(5\right.$ and $\left.9{ }^{\circ} \mathrm{C}\right)$ with or without the use of a fixed thermal screen were studied for cv. "Marbello". This experiment was carried out between 24 January and 2 April 1985. In both experiments treatments for night air temperatures and fixed thermal screen were not replicated while soil temperatures were replicated twice per climate treatment. At each harvest 45 heads per replicate were assessed for head formation.

\section{Results}

Significant differences in percentages of open heads were found between the cultivars studied (Table 1). 'Starlina', 'Aubade', 'Cristallo', and 'Kellys' performed a poor head quality with percentages of open heads between 18 and $38 \%$. In Fig. 1 a typical example of an open and a well-closed head is shown. 'Sonia' and 'Marbello' appeared to be much less susceptible to this unfavourable property; in both cultivars the occurrence of open heads remained below $10 \%$. From Table 1 no relationship between head form and head weight can be deduced.

In Fig. 2 the effects of changes in temperature of the root environment of $\mathrm{cv}$.

Table 1. Proportion of open heads (\%) and head weight ( $\mathrm{g} / \mathrm{head})$ of iceberg lettuce cultivars. Values are means of three sites and two replicates per site.

\begin{tabular}{lll}
\hline Cultivar & Open heads & Head weight \\
& & \\
Starlina & $37.7 \mathrm{a}^{\mathrm{l}}$ & $480 \mathrm{~b}$ \\
Aubade & $30.0 \mathrm{a}$ & $502 \mathrm{a}$ \\
Cristallo & $22.6 \mathrm{a}$ & $525 \mathrm{a}$ \\
Kellys & $18.1 \mathrm{a}$ & $557 \mathrm{a}$ \\
Sonia & $9.7 \mathrm{~b}$ & $514 \mathrm{a}$ \\
Marbello & $9.4 \mathrm{~b}$ & $546 \mathrm{a}$ \\
Significance level & $1 \%$ & $10 \%$ \\
\hline
\end{tabular}

' $a$ and $b$ values differ significantly at significance levels mentioned.
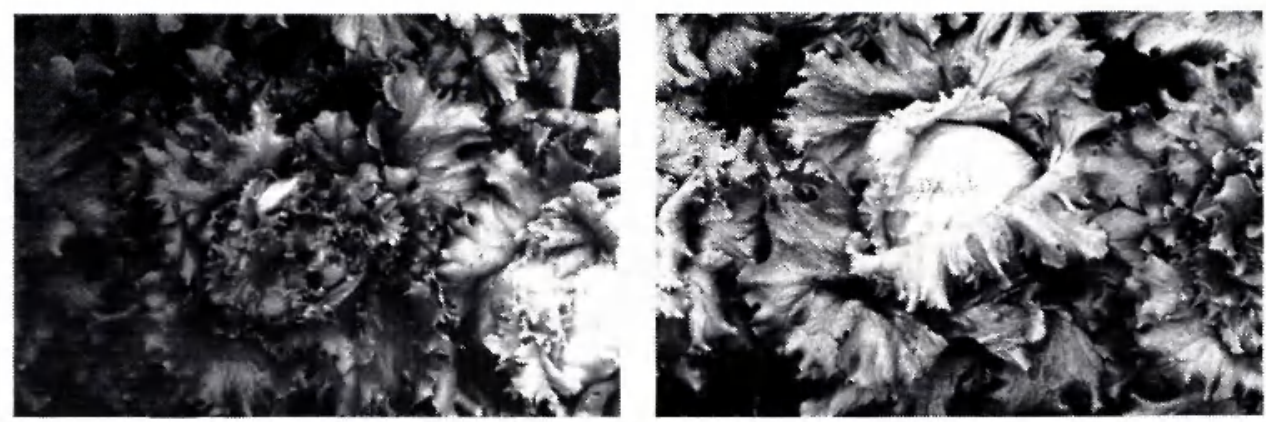

Fig. 1. Typical perfomance of an open (A, left) and a well-closed (B-right) head of iceberg lettuce cv. 'Cristallo'. 


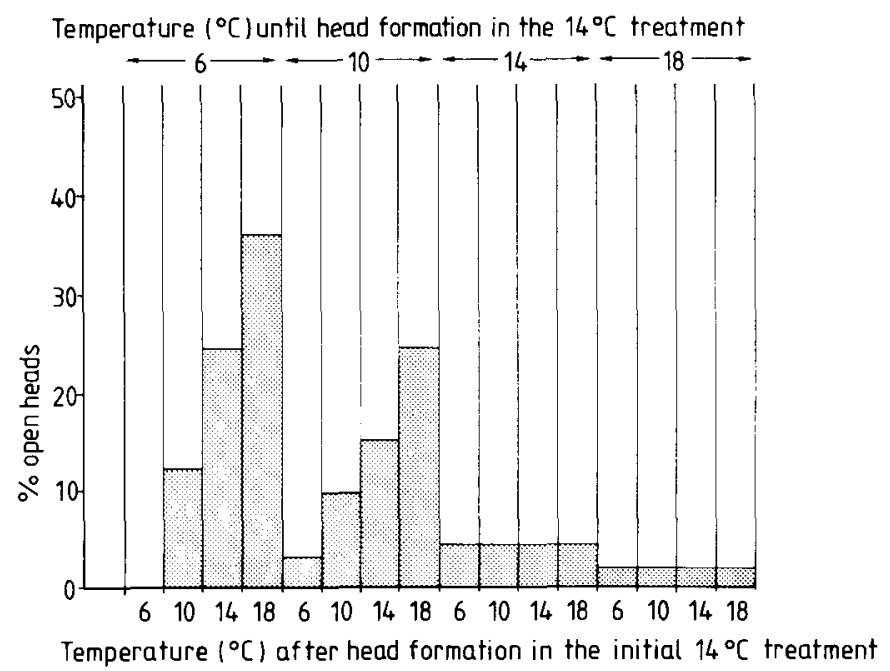

Fig. 2. Proportion of open heads in iceberg lettuce cv, 'Cristallo' as affected by different temperature regimes in the root enviroment. Root temperatures were changed at the moment that head formation started in the $14^{\circ} \mathrm{C}$ treatment.

'Cristallo' are shown. With high soil temperatures $\left(14\right.$ or $\left.18^{\circ} \mathrm{C}\right)$ during the first part of the growing period, no effect of temperature after the onset of head formation was observed with respect to head quality. Increased numbers of open heads were observed at low $\left(6\right.$ or $\left.10^{\circ} \mathrm{C}\right)$ root temperatures during the first part of the growing

Table 2. Open heads (\%) and head weight (g/head) of iceberg lettuce crs. 'Cristallo' (Exp. 1) and 'Marbello' (Exp. 2) grown at different soil temperatures and night air temperatures, with or without the use of a fixed thermal screen.

\begin{tabular}{|c|c|c|c|c|c|}
\hline \multirow[t]{2}{*}{ Experiment } & \multirow{2}{*}{$\begin{array}{l}\text { Night air } \\
\text { temperatue } \\
\left({ }^{\circ} \mathrm{C}\right)\end{array}$} & \multicolumn{2}{|c|}{ With thermal screen } & \multicolumn{2}{|c|}{ Without thermal sceen } \\
\hline & & $\begin{array}{l}\text { soil temp. } \\
14{ }^{\circ} \mathrm{C}\end{array}$ & $\begin{array}{l}\text { variable } \\
\text { soil temp. }\end{array}$ & $\begin{array}{l}\text { soil temp. } \\
14{ }^{\circ} \mathrm{C}\end{array}$ & $\begin{array}{l}\text { variable } \\
\text { soil temp. }\end{array}$ \\
\hline & & \multicolumn{2}{|c|}{ Open heads (\%) } & & \\
\hline \multirow[t]{2}{*}{1} & 7 & 1 & 9 & 13 & 21 \\
\hline & 10 & 0 & 4 & 1 & 9 \\
\hline \multirow[t]{3}{*}{2} & 5 & & 10 & & 27 \\
\hline & 9 & & 3 & & 0 \\
\hline & & \multicolumn{2}{|c|}{ Head weight (g/head) } & & \\
\hline \multirow[t]{2}{*}{1} & 7 & 507 & 425 & 575 & 472 \\
\hline & 10 & 471 & 476 & 616 & 586 \\
\hline \multirow[t]{2}{*}{2} & 5 & & 290 & & 319 \\
\hline & 9 & & 362 & & 430 \\
\hline
\end{tabular}

${ }^{1}$ Temperature at $10 \mathrm{~cm}$ depth equal to ambient temperature. 
period followed by higher temperatures thereafter (Fig. 2). The number of open heads increased as the temperature shifts were larger (about $14 \%$ of open heads in the 6-10 and 10-14 treatments, about $24 \%$ in the 6-14 and 10-18 treatments, and about $36 \%$ in the 6-18 treatment). The temperature combination $6-6$ and $10-6$ gave poor growth and unreliable results, whereas maintaining the root temperature at levels higher than $14^{\circ} \mathrm{C}$ throughout the growing period resulted in a low percentage of open heads.

Percentages of open heads and head weights at different combinations of soil temperatures and night air temperatures with and without the use of a fixed thermal screen are given in Table 2 . The results clearly indicate that application of a thermal screen in combination with higher soil and night air temperatures resulted in less open heads. Head weights were also higher at higher night air temperatures, but were lower in the treatments where the thermal screens were used. These data could not be analysed statistically.

\section{Discussion}

In iceberg lettuce significant differences were found between cultivars with respect to both proportion of open heads and mean head weight (Table 1). There seems to be no relation to the occurrence of open heads and head weight. Breeding for acceptable head formation without repercussions in terms of yield reduction seems therefore to be a promising practice.

Maintaining relatively high temperatures in the root environment throughout the growing period will reduce the risk of the formation of open heads considerably (Fig. 2). From our results is has become evident that formation of open heads is restricted to conditions where a low temperature in the root evironment during the period until head formation is followed by higher temperatures thereafter. The extent of this temparature shift is correlated with resulting proportion of open heads (Fig. 2). These results may be explained by the prompt increase in growth of both roots and shoot caused by such increased root temperature. The above-ground growing point of iceberg lettuce is very close to soil level and it is thus very likely that soil temperature will affect the air temperature around the above-ground growing point in such cases. The results of the experiment in soil confirm this supposition, since night air temperature had a greater positive effect on head formation than soil temperature (Table 2).

The favourable influence of the use of a fixed thermal screen on head quality, i.e. reduced proportion of open heads, may be explained by lower energy losses and hence higher plant temperature. However, application of a thermal screen resulted in a reduction of the head weight (Table 2), probably due to continuous shading (Gray \& Steckel, 1981). This yield reduction can be partly or wholly compensated by the maintenance of a relatively high soil and night air temperature (Table 2), allowing a high rate of leaf production (Bensink, 1971). 
R. H. M. MAASWINKEL AND G. W. H. WELLES

\section{References}

Bensink, J., 1971. On morphogenesis of lettuce leaves in relation to light and temperature. Mededelingen Landbouwhogeschool Wageningen, 71.15.

Gray, D. \& J. R. A. Steckel, 1981. Hearting and mature head characteristics of lettuce (Lactuca sativa L.) as affected by shading at different periods during growth. Journal of Horticultural Science 56: 199-206.

Norman, B., 1985. Crisp lettuce loses premium it needs. Grower 103(20): 6. 